\title{
Role, implementation, and effectiveness of advanced allied health assistants: a systematic review
}

This article was published in the following Dove Press journal: Journal of Multidisciplinary Healthcare

29 November 2013

Number of times this article has been viewed

\author{
Jessica Stanhope' \\ Claire Pearce ${ }^{2}$ \\ 'International Centre for Allied \\ Health Evidence, University of South \\ Australia, Adelaide, SA, Australia; \\ ${ }^{2}$ ACT (Australian Capital Territory) \\ Government Health Directorate, \\ Canberra, ACT, Australia
}

Background: The purpose of this systematic review was to determine the effectiveness and implementation of advanced allied health assistant roles.

Methods: A systematic search of seven databases and Google Scholar was conducted to identify studies published in English peer-reviewed journals from 2003 to 2013 and reporting on the effectiveness and implementation of advanced allied health assistant (A/AHA) roles. Reference lists were also screened to identify additional studies, and the authors' personal collections of studies were searched. Studies were allocated to the National Health and Medical Research Council hierarchy of evidence, and appraisal of higher-level studies (III-1 and above) conducted using the Centre for Evidence Based Medicine Systematic Review Critical Appraisal Sheet for included systematic reviews or the PEDro scale for level II and III-1 studies. Data regarding country, A/AHA title, disciplines, competencies, tasks, level of autonomy, clients, training, and issues regarding the implementation of these roles were extracted, as were outcomes used and key findings for studies investigating their effectiveness.

Results: Fifty-three studies were included, and most because they reported background information rather than investigating A/AHA roles, this representing low-level information. A/AHAs work in a range of disciplines, with a variety of client groups, and in a number of different settings. Little was reported regarding the training available for A/AHAs. Four studies investigated the effectiveness of these roles, finding that they were generally well accepted by clients, and provided more therapy time. Issues in integrating these new roles into existing health systems were also reported.

Conclusion: A/AHA roles are being implemented in a range of settings, and appear to be effective in terms of process measures and stakeholder perceptions. Few studies have investigated these roles, indicating a need for research to be conducted in this area to enable policy-makers to consider the value of these positions and how they can best be utilized.

Keywords: allied health, assistant, advanced, systematic review, effectiveness, role

\section{Introduction}

The shortage of health professionals in Australia has led governments to consider workforce redesign to utilize better their human resources to meet the health needs of the population. One aspect of redesign in the health workforce is advanced practice or extended scope roles. Advanced scope of practice refers to "a role that is within the currently recognized scope of practice for that profession, but that through custom and practice has been performed by other professions. The advanced role would require additional training, competency development, as well as significant clinical experience and formal peer recognition. This role describes the depth or practice", ${ }^{1}$ whilst extended scope of practice is defined as "a role that is outside the currently recognized scope of practice
Correspondence: Claire Pearce ACT Government Health Directorate, GPO Box 825, Canberra City, ACT 260I, Australia

Tel +6I 262050893

Fax +6I 262052037

Email claire.pearce@act.gov.au
Journal of Multidisciplinary Healthcare 20I 3:6 423-434 
and requires legislative change. Extended scope of practice requires some method of credentialing following additional training, competency development, and significant clinical experience... This role describes the breadth of practice". ${ }^{1}$

Although advanced/extended practice is most commonly associated with nurse practitioner roles, and extended scope physiotherapists, there is also a shift towards expanding the roles of allied health assistants (AHA). The current scope of practice of AHAs was reported in a recent systematic review, ${ }^{2}$ with duties including assisting allied health professionals, providing physical and social support to patients, administering clinical services and modalities, transferring patients, communicating patient progress, communicating with other staff, assisting with mobility and gait, providing equipment, patient education, provision of health care to patients, supervising/ conducting exercise classes, preparing patients for treatment, conducting individual or group therapy, coordinating and assisting in the operation of services, assisting and coordinating health service, administration, stock ordering/requisition, preparing/maintaining the environment, maintaining equipment, health promotion, monitoring and updating health care databases, recording/statistics/database, housekeeping, and cleaning. This systematic review did not report the role of advanced allied health assistants (A/AHA), although there are examples of advanced roles being implemented in Australia, highlighting the need for a more specific review in this area. In better understanding these roles, and how they have been implemented elsewhere, policy-makers will be better able to determine whether such roles are worthwhile, how they can best be utilized, and potential issues in the implementation of $\mathrm{A} / \mathrm{AHA}$ roles.

The working definition of A/AHA used for the purpose of this review is any assistant role supporting allied health professionals, working beyond the skill base or level of responsibility normally expected for an AHA. It is acknowledged that there is likely to be a range of terms used to describe these roles, eg, advanced, senior, or extended scope, as well as terms reflecting the allied health disciplines they support (eg, physiotherapy, occupational therapy), or more generic health care terms (eg, health care assistant, support worker).

This systematic review sought to answer the following questions:

1 What is the scope of practice of A/AHAs?

2 What client groups do A/AHAs work with?

3 What settings do A/AHAs work in?

4 What training is available for A/AHAs?

5 How effective are A/AHA roles in terms of health, cost, and process outcomes?

6 What are the workforce issues for A/AHAs?

\section{Materials and methods}

\section{Systematic search}

A systematic search of key library databases (Embase [OvidSP], Medline [OvidSP], Scopus, Web of Science, Nursing and Allied Health Source [ProQuest], Health and Medical Complete [ProQuest], and Cumulative Index to Nursing and Allied Health Literature [CINAHL], EbscoHost) was conducted in February 2013, using a comprehensive list of search terms (see http://www.unisa.edu.au/PageFiles/68220/ AAHA\%20paper\%20appendix\%20pdf\%20(2).pdf). These terms were developed through iterative discussion and by consulting systematic reviews of AHA roles. ${ }^{2,3}$ These terms were searched in all fields, and limited to peer-reviewed studies published in English from 2003 to 2013 where permitted by the databases. Additionally, a similar search was conducted in Google Scholar using the same terms (see http:// www.unisa.edu.au/PageFiles/68220/AAHA \%20paper $\% 20$ appendix $\% 20 \mathrm{pdf} \% 20(2) . p d f)$. This search was also limited to 2003-2013.

To widen the search, the reference lists of all included peer-reviewed studies, and the reference lists of any systematic reviews identified through the search were manually screened to identify any study titles which made reference to A/AHA, or which referenced A/AHA in the text. Additionally, the authors screened their personal collections of studies for any relevant information. If further studies were included, this process was repeated until saturation was reached.

\section{Study identification}

All studies obtained were exported into EndNote X6 where duplicate studies were excluded. The titles and abstracts of all remaining studies was screened, before the full texts were obtained and screened. Studies were excluded if they:

- did not involve A/AHA (eg, the assistant was not identified as advanced, senior, or extended scope, or did not perform tasks identified as extended scope or advanced practice, or they clearly stated that their role was to support non-AHA staff, eg, nurses)

- only reported potential A/AHA roles, rather than those which had been implemented

- were not published between 2003 and 2013 (or where no date could be determined)

- were not published in English

- were not available in full text (eg, conference abstracts)

- were not published in peer-reviewed journals

- did not include any information pertaining to the six review questions.

Due to the broad nature of questions for this review, studies of any design were included. Furthermore, any paper 
reporting relevant data was included, even if this was not investigated in the study (eg, relevant information for this review was reported in the background). Where this relevant information was citing another reference, the original study was identified to ensure it (the original study) met the inclusion criteria. Where all relevant information was cited from other references, the study was excluded.

\section{Assigning levels of evidence}

Where the findings of a study informed the review questions (ie, not solely background information) the study design was identified, and assigned to the National Health and Medical Research Council (NHMRC) hierarchy of evidence. ${ }^{4}$

\section{Critical appraisal}

Critical appraisal was only conducted for studies identified as level III-1 or higher. Systematic reviews were appraised using the Centre for Evidence Based Medicine Systematic Review Critical Appraisal Sheet, ${ }^{5}$ and the PEDro scale ${ }^{6}$ was used for level II and III-1 studies. Lower-level studies were not appraised due to the biases inherent in their designs.

\section{Data extraction}

Relevant data were extracted from all included studies, according to the headings reported in Table 1. Where relevant information was reported with a reference, the data were not extracted, but the reference was obtained and included in the review if it met the inclusion criteria.

\section{Analysis}

Due to the nature of the questions posed, all data are reported descriptively.

\section{Results}

Of the 1,987 studies identified through searching of the database/Google Scholar, 52 were included, with one additional study ${ }^{7}$ meeting the inclusion criteria already known to the authors also included (see Figure 1 for the flow chart). Table 2 reports the A/AHA roles reported in the literature, as well as the countries in which they have been implemented.

\section{Question I: what is the scope of practice of A/AHAs?}

Allied health disciplines

A/AHAs work in a range of disciplines, including pharmacy, social work, psychology, occupational therapy, physiotherapy, podiatry, and dietetics (see Table 3). Some studies $^{8-13,16-20,22-25,27,28,31-33,36,37}$ did not report which allied
Table I Data extraction

\begin{tabular}{|c|c|}
\hline General & $\begin{array}{l}\text { - Country } \\
\text { - Study design } \\
\text { - Title of the A/AHA }\end{array}$ \\
\hline $\begin{array}{l}\text { Question I: what is the scope } \\
\text { of practice of } A / A H A \text { ? }\end{array}$ & $\begin{array}{l}\text { - AH discipline they support } \\
\text { - Competencies of the A/AHA role } \\
\text { - Tasks performed which directly } \\
\text { or indirectly involve patient } \\
\text { care (eg, not audits for research } \\
\text { purposes) } \\
\text { - Level of autonomy }\end{array}$ \\
\hline $\begin{array}{l}\text { Question 2: what client } \\
\text { groups do A/AHA work with? } \\
\text { Question 3: what settings } \\
\text { do A/AHAs work in? }\end{array}$ & $\begin{array}{l}\text { - Age groups } \\
\text { - Conditions } \\
\text { - Any setting they work in }\end{array}$ \\
\hline $\begin{array}{l}\text { Question 4: what training } \\
\text { is available for } \mathrm{A} / \mathrm{AHA} \text { ? }\end{array}$ & $\begin{array}{l}\text { Any type of training (formal } \\
\text { or informal) either enabling } \\
\text { them to work as A/AHAs or to } \\
\text { extend their skills in this role (ie, } \\
\text { professional development) }\end{array}$ \\
\hline $\begin{array}{l}\text { Question 5: how effective are } \\
\text { A/AHA roles in terms of health, } \\
\text { cost and process outcomes? }\end{array}$ & $\begin{array}{l}\text { - A/AHA role implemented } \\
\text { - Outcome measures used } \\
\text { - Key findings }\end{array}$ \\
\hline $\begin{array}{l}\text { Question 6: what are the } \\
\text { workforce issues for A/AHA? }\end{array}$ & $\begin{array}{l}\text { - Any issues identified, including } \\
\text { but not limited to changing roles } \\
\text { of others (eg, AHA or AHP), and } \\
\text { funding }\end{array}$ \\
\hline
\end{tabular}

Note: anless otherwise stated this was assumed to be the same as the author's affiliations.

Abbreviations: A/AHA, advanced allied health assistant; $\mathrm{AHA}$, allied health assistant; AHP, allied health professional.

health discipline the assistant worked in; however, they were included in this review because they did not clearly state that they were supporting a role outside of the allied health professions (eg, medical). This section of the review was informed by 33 studies; however, none of these studies specifically researched the disciplines, so these data cannot be allocated to the hierarchy of evidence.

\section{Competencies}

A qualitative study ${ }^{7}$ (NHMRC level not assigned) reported the competencies required of an extended role occupational therapy support worker. These were the ability to make sound judgments, interpersonal skills (eye contact, "nice disposition", friendly), interest in the job, communication skills, confidence, need to be able to assert their own role boundaries/competence/ confidence, drive, have developed the role themselves, assertiveness, initiative, ability to "think outside the box", need for self-direction, trustworthy (more than just a police check), ability to think/reflect on role, type of people who will continually improve (eg, undertake training), experience, training to underpin competence, formal qualifications, willing to accept responsibility, willing to learn, and clinical competence. ${ }^{7}$ 


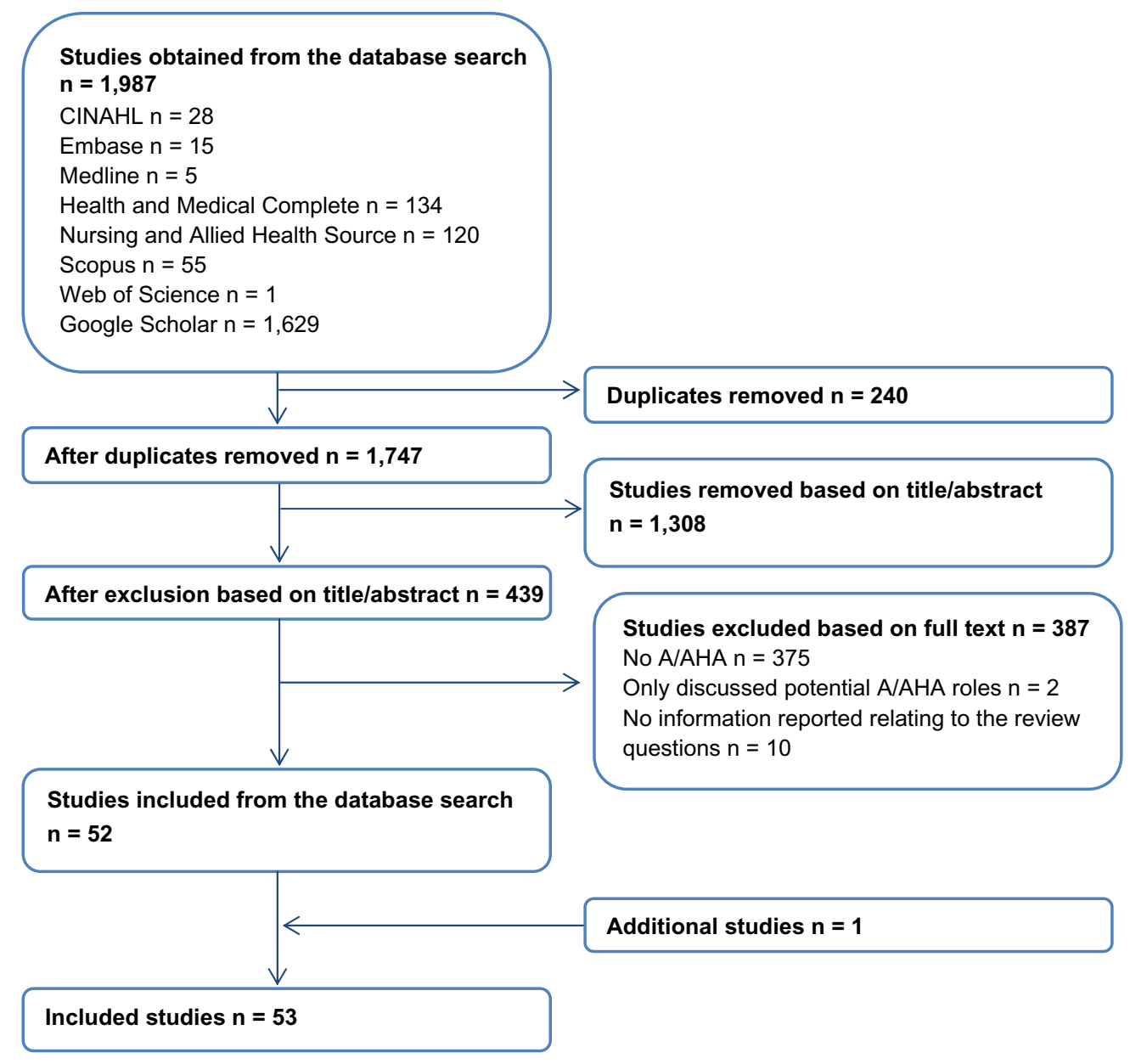

Figure I Flow chart for database search.

Abbreviations: CINAHL, Cumulative Index to Nursing and Allied Health Literature; A/AHA, advanced allied health assistant.

Tasks performed and level of autonomy

The tasks performed by A/AHAs, including their level of autonomy, are reported in Table 4. This section drew upon 22 studies; however, only one study ${ }^{44}$ (cross-sectional cohort, NHMRC level III-3) investigated the advanced tasks being performed by A/AHAs.

\section{Question 2: what client groups do A/AHAs work with?}

Twenty-six studies reported the client groups in which A/AHAs worked, but none of these studies investigated this, so no study was allocated to the NHMRC hierarchy of evidence. A/AHAs work with both adults and children with a range of conditions, including intellectual/ learning disabilities, emotional, behavioral, and/or social difficulties, neurologic conditions, dementia, cancer, postsurgery (including total hip replacement), mental health problems, mobility problems, and those at risk of falls (see Table 5).

\section{Question 3: what settings do A/AHAs work in?}

A/AHAs work in various settings, including clients' homes, community services, and hospitals (see Table 6). All data reported for this question were regarded as providing background information (ie, not from the research findings) for 30 studies, and were therefore not allocated to the hierarchy of evidence.

\section{Question 4: what training is available for A/AHAs? \\ Formal training}

In Australia, the Certificate IV in Allied Health Assistance was reported as a formal qualification for A/AHAs (one study, ${ }^{38}$ background information, NHMRC level not assigned). Further, a Certificate IV level qualification in Hospital/Health Services Pharmacy Support was held by some of the pharmacy technicians/assistants in O'Leary's ${ }^{44}$ study (cross-sectional cohort, NHRMC level III-3), but not 
Table 2 Advanced allied health assistant terms used and the countries in which advanced allied health assistants work

\begin{tabular}{ll}
\hline Advanced allied health assistant & Countries \\
\hline Senior support worker & UK $^{8-24,25}$ \\
& Australia $^{26-28}$ \\
& USA $^{29,30}$ \\
Senior health care assistants/senior support workers & UK $^{22,31}$ \\
Senior health care support worker & UK $^{32}$ \\
Senior health care assistant & UK $^{33,34}$ \\
Senior health care assistant/assistant practitioner & UK $^{35}$ \\
Advanced practice health care aides & Canada $^{36}$ \\
Senior rehabilitation technician & USA $^{37}$ \\
Advanced community rehabilitation assistant & Australia $^{38}$ \\
Senior occupational therapy assistant & UK $^{39}$ \\
Extended role occupational therapy support & UK $^{7}$ \\
worker/occupational therapy assistant practitioner & \\
Senior social worker assistants & Hong Kong $^{40,41}$ \\
Senior social work assistant & UK $^{42}$ \\
Physical therapy assistants taking & USA $^{43}$ \\
on advanced-level opportunities & \\
Pharmacy technicians/assistants & Australia $^{44}$ \\
with advanced practice roles & \\
Pharmacy technician with extended roles & Australia $^{45}$ \\
Advanced practice pharmacy technicians & USA $^{46}$ \\
Senior pharmacy technician & The Netherlands $^{47}$ \\
& Canada $^{88,49}$ \\
Senior pharmacy assistant & Australia $^{50,51}$ \\
\hline & UK $^{52-59}$ \\
Malaysia $^{60}$ \\
\hline
\end{tabular}

all of them, highlighting the inconsistencies in the level of education required to undertake these advanced roles.

In the United Kingdom, expanded role occupational therapy support workers/advanced practitioners had completed National Vocational Qualification training. ${ }^{7}$ However, there was a perception reported in this qualitative study (NHMRC level not assigned) that a number of the skills/attributes that the A/AHA requires could only be gained through experience, rather than the formal "paper" qualification. ${ }^{7}$

Informal training

Informal training for A/AHAs was also reported in two studies $^{46,55}$ (background information, NHRMC level not assigned). For advanced practice pharmacy technicians, a self-learning package was used and was developed inhouse. ${ }^{46}$ Informal training for both advanced practice pharmacy technicians and senior pharmacy technicians involved competency assessments. ${ }^{46,55}$

\section{Question 5: how effective are A/AHA roles in terms of health, cost, and process outcomes?}

Process outcomes and stakeholder perspectives (relating to health and processes) were reported in four studies, ${ }^{7,38,46,55}$ but no study reported cost or health outcomes. The main findings

Table 3 Allied health disciplines in which advanced allied health assistants work

\begin{tabular}{|c|c|c|c|c|c|c|c|c|}
\hline $\begin{array}{l}\text { Advanced allied health } \\
\text { assistant title }\end{array}$ & Pharmacy & $\begin{array}{l}\text { Social } \\
\text { work }\end{array}$ & Psychologist & $\begin{array}{l}\text { Occupational } \\
\text { therapy }\end{array}$ & Physiotherapy & $\begin{array}{l}\text { Speech } \\
\text { therapy }\end{array}$ & Podiatry & $\begin{array}{l}\text { Dietetics } \\
\text { nutrition }\end{array}$ \\
\hline Senior support worker & & 21 & $14,15,26,29,30$ & & & & & \\
\hline Senior health care assistant & & 34 & & & & & & \\
\hline $\begin{array}{l}\text { Senior health care assistant/ } \\
\text { assistant practitioner }\end{array}$ & & & & & 35 & & & \\
\hline Advanced allied health assistants & & & & 3 & & & & \\
\hline $\begin{array}{l}\text { Advanced community } \\
\text { rehabilitation assistant }\end{array}$ & & & & 38 & 38 & 38 & 38 & 38 \\
\hline $\begin{array}{l}\text { Senior occupational } \\
\text { therapy assistant }\end{array}$ & & & & 39 & & & & \\
\hline $\begin{array}{l}\text { Extended role occupational } \\
\text { therapy support worker/ } \\
\text { occupational therapy } \\
\text { assistant practitioner }\end{array}$ & & & & 7 & & & & \\
\hline Senior social worker assistants & & $40,4 I$ & & & & & & \\
\hline Senior social work assistant & & 42 & & & & & & \\
\hline $\begin{array}{l}\text { Physical therapy assistants taking } \\
\text { on advanced-level opportunities }\end{array}$ & & & & & 43 & & & \\
\hline $\begin{array}{l}\text { Pharmacy technicians/assistants } \\
\text { with advanced practice roles }\end{array}$ & 44 & & & & & & & \\
\hline $\begin{array}{l}\text { Pharmacy technician } \\
\text { with extended roles }\end{array}$ & 45 & & & & & & & \\
\hline $\begin{array}{l}\text { Advanced practice } \\
\text { pharmacy technicians }\end{array}$ & 46 & & & & & & & \\
\hline Senior pharmacy technician & $47-59$ & & & & & & & \\
\hline Senior pharmacy assistant & 60 & & & & & & & \\
\hline
\end{tabular}

Note: Numbers in table refer to references supporting data. 
Table 4 Tasks performed by advanced allied health assistants

Advanced allied health assistant
Senior support worker
Advanced practice health care aides
Advanced community rehabilitation
assistant

Senior occupational therapy assistant Extended scope occupational therapy support worker

Advanced practice role for pharmacy technicians/assistants

Advanced practice tasks for pharmacy technicians

Advanced practice pharmacy technicians

Senior pharmacy technician

Senior pharmacy assistant
Tasks and level of autonomy

- Supervise support workers ${ }^{15,30}$

- Assist psychologists in training and supervising support workers, and running a parent's group, along with the psychologist ${ }^{16}$

- Discuss assessments of children with the support worker who carried out these assessments ${ }^{29}$

- Involved in falls prevention program ${ }^{36}$

- Conduct interventions including self-care, domestic tasks, physical programs, community access and integration, domestic tasks, leisure, advocacy for clients at medical appointments, speech and communication, monitoring medication compliance and basic wound care, in individual and group settings, phone, and face-to-face ${ }^{38}$

- Work under the supervision of an AHP or nurse ${ }^{38}$

- Work with more autonomy than an $\mathrm{AHA}^{38}$

- Advised patients regarding hip precautions ${ }^{39}$

- Works autonomously on an occupational therapy caseload ${ }^{7}$

- Can assess the need for and deliver occupational therapy management strategies, within their professional boundaries ${ }^{7}$

- Are supervised by an occupational therapist, but has responsibility for the progress of their clients ${ }^{7}$

- Is managed by a team leader and an occupational therapist ${ }^{7}$

- Can perform occupational therapy and generic tasks in a range of social and health care settings ${ }^{7}$

- Extemporaneous compounding (eg, aseptic admixtures, aseptic cytotoxic admixtures) ${ }^{44}$

- Provide research support ${ }^{44}$

- Processing claims, new admissions ${ }^{44}$

- Assist the pharmacist with clinical review tasks ${ }^{44}$

- Assist the pharmacist with therapeutic drug monitoring activities ${ }^{44}$

- Provide medicine information to other health professionals and to patients ${ }^{44}$

- Provide information for ongoing care, monitoring adverse drug reaction ${ }^{44}$

- Conduct quality control activities ${ }^{44}$

- Answering phones ${ }^{45}$

- Posting mail 45

- Photocopying ${ }^{45}$

- Entering patent data ${ }^{45}$

- Deal with patent billing queries ${ }^{45}$

- Notify the billings department of any high cost drugs supplied via the imprest system ${ }^{45}$

- Validate the work of other technicians where nonjudgmental pharmacy functions are performed (tech-check-tech) a task usually performed by a pharmacist ${ }^{46}$

- Prepare compound cytotoxic drugs ${ }^{51}$

- Have a supervisory role $^{48} /$ team leader $^{49}$

- Analyze the prescription of drugs ${ }^{59}$

- Take medication histories ${ }^{58}$

- Have an involvement in the transition from hospital to intermediate care ${ }^{58}$

- Liaise between the patient, medical/nursing staff, community pharmacist and/or general practitioner ${ }^{58}$

- Ensure legibility and accuracy of discharge prescriptions and/or medicines administration records ${ }^{58}$

- Assess the patient's understanding of medications and the potential issues with self-administration ${ }^{58}$

- Educate the patients and their families about their medications ${ }^{58}$

- Provide support and guidance to students in a foundation degree in medicines management course, and as a work-based facilitator ${ }^{53}$

- Lead a drug administration round (oral medicines only), and a nurse would take the lead for complex patients if the senior pharmacy technician did not feel comfortable ${ }^{55}$

- Educate students and return to practice nurses who follow on in the drug administration rounds ${ }^{55}$

- Coordinate the medical gases service, which included policy implementation, receiving the new cylinders, coordination of the collection of old cylinders, charging the cylinders to the users (wards, departments, special schools), arranging the store room and completing the associated paper work ${ }^{56}$

- Front line for screening for prescriptions reviewed by the outpatient pharmacy department, which were then referred to a trainee pharmacist or pharmacist ${ }^{60}$ 
Table 4 (Continued)

\begin{tabular}{ll}
\hline Advanced allied health assistant & Tasks and level of autonomy \\
\hline Advanced allied health assistant & - Practice autonomously \\
& - Have primary contact status ${ }^{3}$ \\
& - Provide plan care programs \\
& - Make decisions regarding interventions ${ }^{3}$ \\
& - Discharge patients ${ }^{3}$ \\
Senior health care assistant/assistant & - Screen for falls risk \\
practitioner & - Assist the patient with walking and exercising following instructions provided by a physiotherapist ${ }^{35}$ \\
\hline
\end{tabular}

were that the A/AHA role appears to be well accepted by clients, provides clients with more therapy time, and frees up time for allied health professionals to perform other duties. The details of the effectiveness of A/AHA roles are reported in Table 7. It should be noted that none of these studies were of high-level design. Consequently, there are inherent biases in the study designs, which reduce the believability of these findings.

\section{Question 6: what are the workforce issues for $\mathrm{A} / \mathrm{AHA}$ ?}

Two qualitative studies ${ }^{7,38}$ (NHMRC level not assigned) reported the issues associated with implementing A/AHA

Table 5 Client groups that advanced allied health assistants work with

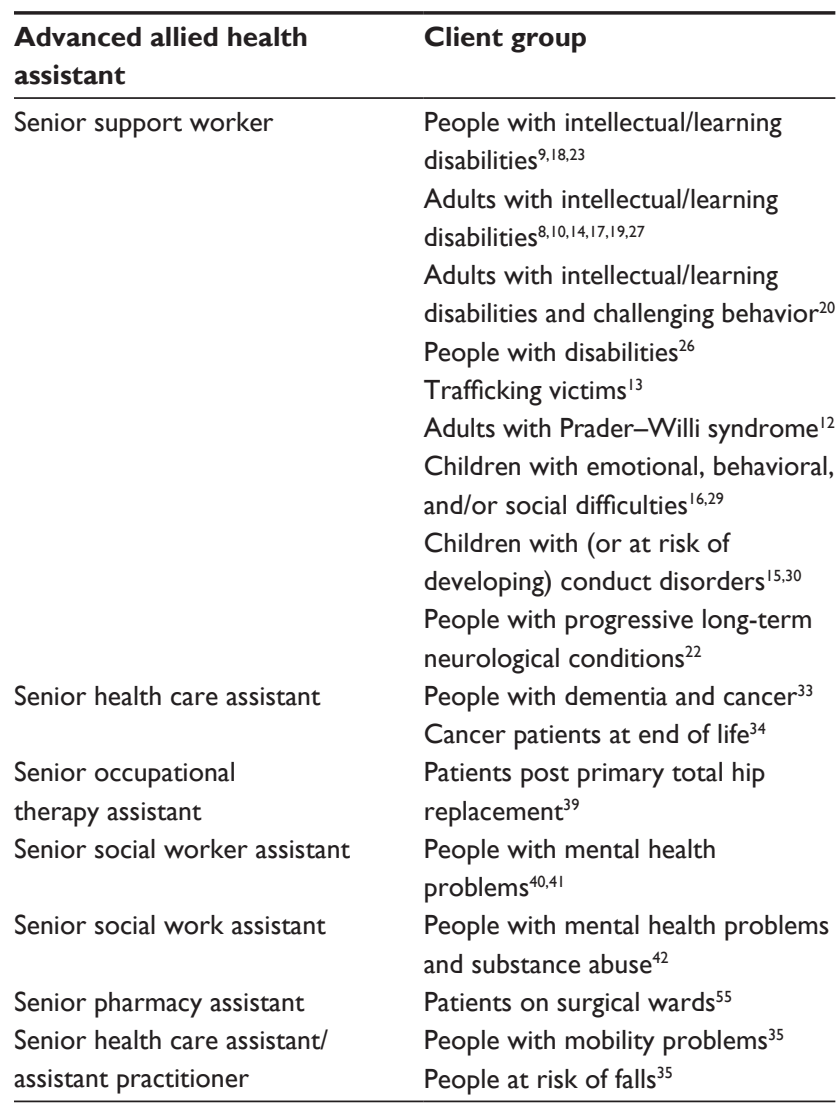

roles. A key issue was the uncertainty of the scope of practice of $\mathrm{A} / \mathrm{AHA},{ }^{7,38}$ concerns relating to how they should be best utilized, ${ }^{38}$ as well as issues around responsibility and accountability. ${ }^{7,38}$ In some cases, the allied health professionals had to spend more time supervising and training the A/AHA in the initial stages. ${ }^{38}$ One study ${ }^{7}$ reported both undersupervision and oversupervision of the A/AHA, which may have been due to lack of understanding of the A/AHA role and the training provided to these assistants. Specific to the advanced community rehabilitation assistant role, time management was an issue because the A/AHA had to report to and communicate with a range of supervisors. ${ }^{38}$ Some allied health professionals felt that the A/AHA were a cheap alternative to their own role; ${ }^{7}$ however, in another study, ${ }^{38}$ an A/AHA felt that their remuneration was insufficient given the additional responsibility of the role. These factors need to be considered in implementing A/AHA roles.

\section{Discussion}

This systematic review is the first investigating the roles, implementation, and effectiveness of A/AHAs. This review therefore provides the first high-level synthesis of literature, providing a greater overview of the scope and effectiveness of the A/AHA role than the primary literature. The published research is low-level (NHMRC level III-3 or not assigned), and for some research questions there were few relevant studies identified, limiting the conclusions that can be drawn from this review. This lack of evidence highlights the need for greater research into the area of A/AHA roles.

A/AHA roles are diverse in terms of the disciplines they work with, as well as their work settings, tasks, and titles. This diversity presents challenges in defining such a role, and therefore providing appropriate training for these roles. A/AHA roles are likely to have emerged within a specific health service to meet unique needs, thus leading to ambiguity in what the role actually entails. This is not unique to A/AHA, given that systematic reviews regarding AHA roles 


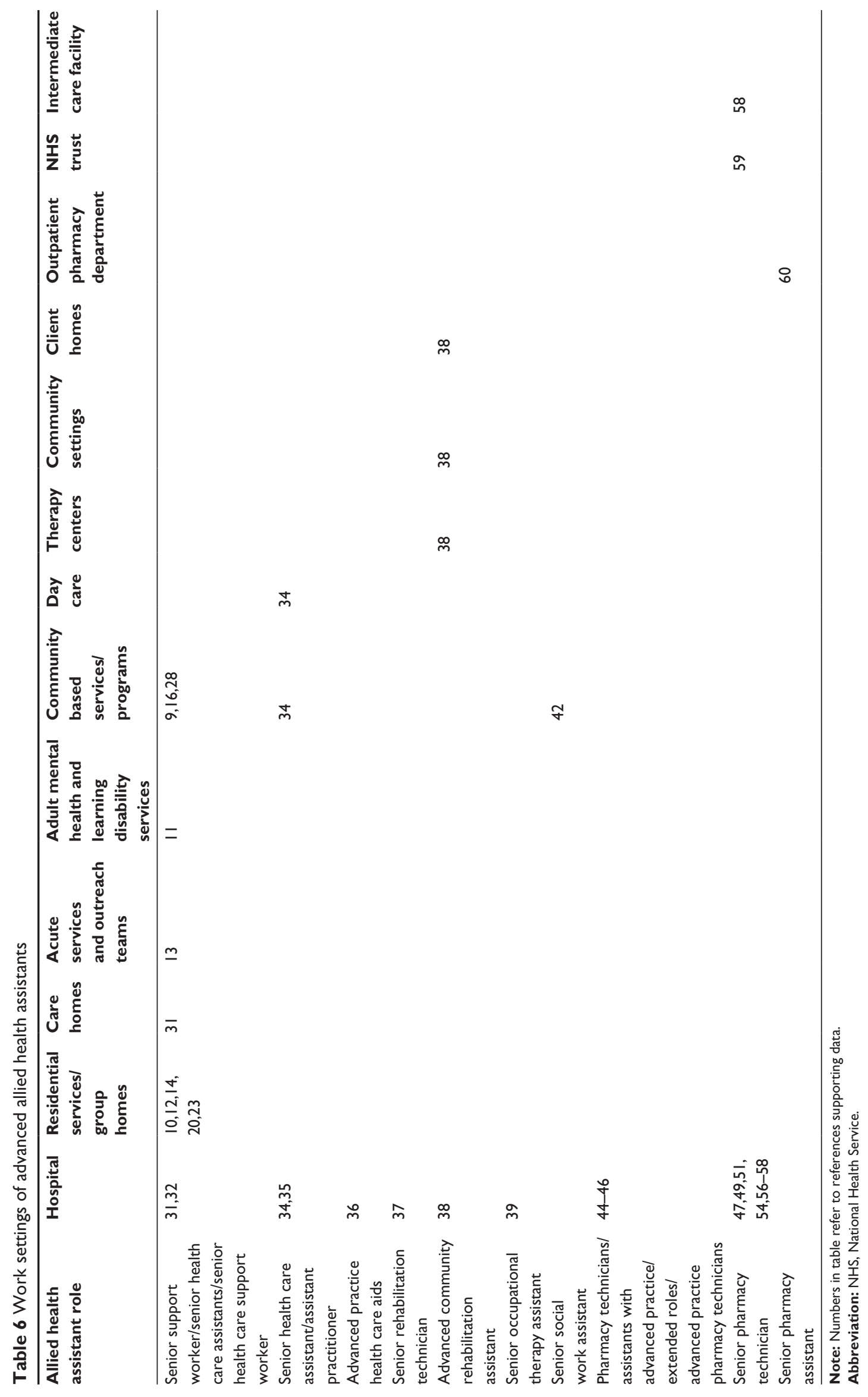


Table 7 Key findings regarding the effectiveness of advanced allied health assistant roles

\begin{tabular}{|c|c|c|c|c|}
\hline Study & $\begin{array}{l}\text { Study design } \\
\text { (NHMRC } \\
\text { level) }\end{array}$ & $\begin{array}{l}\text { Advanced allied } \\
\text { health assistant } \\
\text { role implemented }\end{array}$ & Comparison & Key findings \\
\hline $\begin{array}{l}\text { Nancarrow } \\
\text { and Mackey }\end{array}$ & $\begin{array}{l}\text { Qualitative } \\
\text { (not assigned) }\end{array}$ & $\begin{array}{l}\text { Expanded role } \\
\text { occupational } \\
\text { therapy support } \\
\text { worker }\end{array}$ & OT & $\begin{array}{l}\text { This A/AHA role freed up time for the occupational therapist to } \\
\text { perform other duties. } \\
\text { The A/AHA was reported to spend more time in the client's home } \\
\text { than the occupational therapist, which allowed them to get to know } \\
\text { the patient better, and therefore were better able to manage them } \\
\text { appropriately. } \\
\text { Some support workers as well as managers stated that the support } \\
\text { workers were better able to relate to the patients as they used less } \\
\text { complicated language and had a similar background to their patients. } \\
\text { The patients valued having the additional time with a staff member, } \\
\text { could not differentiate between the A/AHA and occupational therapist, } \\
\text { and they were not concerned about the lack of formalized training, } \\
\text { provided they were trained appropriately. }\end{array}$ \\
\hline Wood et a $\left.\right|^{38}$ & $\begin{array}{l}\text { Qualitative } \\
\text { (not assigned) }\end{array}$ & $\begin{array}{l}\text { Advance community } \\
\text { rehabilitation } \\
\text { assistant }\end{array}$ & AHP & $\begin{array}{l}\text { Clients were satisfied with the A/AHA services, in particular the home } \\
\text { visits were viewed as being valuable, as were the motivation, feedback, } \\
\text { assistance, and monitoring within their therapy programs. } \\
\text { Some clients felt they were getting more therapy with the A/AHA than } \\
\text { they were prior to implementation of these roles. } \\
\text { AHPs reported improvements in client outcomes, which they felt were } \\
\text { due to more frequent and longer therapy sessions. } \\
\text { AHPs reported decreased waiting lists, increased throughput, service } \\
\text { extension and expansion, enhanced multidisciplinary practice, resource } \\
\text { development, and improved ability to provide services under the most } \\
\text { appropriate delivery model. }\end{array}$ \\
\hline $\begin{array}{l}\text { McKee and } \\
\text { Zimmerman }^{46}\end{array}$ & $\begin{array}{l}\text { Non-randomized } \\
\text { blocks, without } \\
\text { concurrent } \\
\text { controls (III-3) }\end{array}$ & $\begin{array}{l}\text { Advanced } \\
\text { practice pharmacy } \\
\text { technicians }\end{array}$ & Pharmacist & $\begin{array}{l}\text { Outcome measures used: time saving for the clinical pharmacist } \\
\text { and the variances. } \\
\text { Implementation of this role saved the clinical pharmacist over } 50 \text { hours } \\
\text { per month, which freed up their time to provide more patient-focused } \\
\text { services. } \\
\text { Variances for the pharmacist in the } 12 \text { months immediately prior to } \\
\text { implementation of the A/AHA role was } 1.42 \text { per month }(95 \% \mathrm{Cl} \\
0.95-1.88) \text {, whereas the variance rate for the advanced practice } \\
\text { pharmacy technician was } 0.3 \mathrm{I} \text { per month }(95 \% \mathrm{Cl} 0.00-0.77) \text {, } \\
\text { indicating greater accuracy of the new role. }\end{array}$ \\
\hline Holding ${ }^{55}$ & $\begin{array}{l}\text { Self-reflection } \\
\text { (not assigned) }\end{array}$ & $\begin{array}{l}\text { Senior pharmacy } \\
\text { technician }\end{array}$ & Nurses & $\begin{array}{l}\text { The senior pharmacy technician reported that there were } \\
\text { improvements in terms of drug security, medicines being delivered in } \\
\text { a more timely manner, and the senior pharmacy technician was able to } \\
\text { explain what the medicines were for and how to take them. }\end{array}$ \\
\hline
\end{tabular}

Abbreviations: NHMRC, National Health and Medical Research Council; A/AHA, advanced allied health assistant; AHP, allied health professional; OT, occupational therapist; $\mathrm{Cl}$, confidence interval.

have also reported this diversity. ${ }^{2}$ The inconsistencies in how AHA roles are defined also has potential implications for defining the A/AHA roles, given that what may be considered an advanced role in one health service may be considered an AHA role in another. This has potential implications for this review, considering that studies had to identify the role as being advanced, extended, or senior to meet the inclusion criteria; hence studies of AHAs which may be considered advanced in some settings may have been missed.

In implementing $\mathrm{A} / \mathrm{AHA}$ roles, stakeholder perspectives have been positive and the roles have been effective in terms of process outcomes, although evidence is low-level. There is currently no evidence regarding the effectiveness of these roles in impacting health or cost outcomes, presenting a clear evidence gap. All included studies regarding the effectiveness of A/AHA compared them with health professionals, rather than with AHAs. Hence the value of implementing A/AHA roles over AHA roles has not been determined. This reveals another area for future research.

A number of issues were reported in terms of fitting the new A/AHA roles into traditional health care models. Prior to implementation, the potential impact on other staff should be considered; strategies should be put in place to ensure that the A/AHAs are appropriately trained, supervised, and 
utilized within the health care system they are working in; and the level of responsibility and accountability of A/AHAs and the supervising allied health professionals needs to be established.

As with any change in the health care system, potential legal issues must also be considered. This was not discussed in implementation of A/AHA roles in any of the included studies. These requirements are likely to differ depending on location, the professions involved, the tasks being performed, and the level of autonomy and accountability assumed by the A/AHA. It should be noted that advanced practice roles by definition are still within the scope of practice of AHAs and are therefore unlikely to have significant legal implications. However, the legal issues would have to be considered carefully before any exploration of extended-scope tasks for AHAs.

\section{Conclusion}

This is the first systematic review, to our knowledge, which has specifically investigated the roles of A/AHAs. The conclusions drawn are limited, due to the quality (low-level designs used, qualitative studies) and quantity of research evidence. Despite this, A/AHA roles are being established in Australia and internationally. These roles are diverse and welcomed by consumers, and there is some suggestion that they are effective in terms of process and health outcomes. Further research in the area should aim to understand the roles better and conduct higher-level studies to determine their effectiveness, particularly in terms of health and cost outcomes. This would enable policy-makers to determine the value of these roles, and how best to utilize them.

\section{Acknowledgments}

We would like to acknowledge Leanne Pagett and Karen Murphy (ACT Health Directorate) for their assistance in developing the project, Karen Grimmer (International Centre for Allied Health Evidence, University of South Australia) for her assistance in developing the search strategy, and Saravana Kumar (International Centre for Allied Health Evidence, University of South Australia) for assisting in the drafting of the manuscript.

\section{Disclosure}

The authors report no conflicts of interest in this work.

\section{References}

1. Australian Physiotherapy Association. Position statement: scope of practice. Australian Physiotherapy Association. Available from: http://www. physiotherapy.asn.au/DocumentsFolder/Advocacy_Position_Scope_of_ Practice_2009.pdf. Accessed November 21, 2011.
2. Lizarondo L, Kumar S, Hyde L, Skidmore D. Allied health assistants and what they do: a systematic review of the literature. $J$ Multidiscip Healthc. 2010;3:143-1153.

3. Lowe J, Grimmer-Somers K, Kumar S, Young A. Allied health scope of practice role development in the wider allied health service delivery context: the allied health assistant (AHA). Prepared for the SA Health and Community Services Skills Board, Government of South Australia. 2008. Available from http://www.health.sa.gov.au/DesktopModules/ SSSA_Documents/LinkClick.aspx?tabid=46\&table=SSSA_Docume nts\&field $=$ ItemID\&id $=874 \&$ link $=\mathrm{T} \% 3 \mathrm{~A} \% 5 \mathrm{C} \_$Online + Services $\% 5 \mathrm{C}$ Web+Admin $\% 5$ CIndividual_site_correspondence $\% 5$ CProject + Corre spondence\%5CAllied+Health\%5CAs. Accessed September 30, 2013.

4. National Health and Medical Research Council. NHMRC additional levels of evidence and grades for recommendations for developers of guidelines: stage 2 Consultation. National Health and Medical Research Council, Australian Government. Available from: http://www.nhmrc. gov.au/_files_nhmrc/file/guidelines/stage_2_consultation_levels_and_ grades.pdf. Accessed January 18, 2013.

5. University of Oxford. Centre for Evidence Based Medicine Systematic Review Critical Appraisal Sheet. Centre for Evidence Based Medicine, University of Oxford. Available from: http://www.cebm.net/index. aspx?o=1157. Accessed February 25, 2013.

6. The George Institute for Global Health. PEDro Scale. PEDro Physiotherapy Evidence Database. Available from: http://www.pedro.org.au/ english/downloads/pedro-scale/. Accessed February 25, 2013.

7. Nancarrow S, Mackey H. The introduction and evaluation of an occupational therapy assistant practitioner. Australian Occupational Therapy Journal. 2005;52:293-301.

8. Bradshaw J, Goldbart J. Staff views on the importance of relationships with knowledge development. J Appl Res Intellect Disabil. 2013;26: 284-298.

9. Stimpson A, Kroese BS, MacMahon P, et al. The experiences of staff taking on the role of lay therapist in a group-based cognitive behavioural therapy anger management intervention for people with intellectual disabilities. J Appl Res Intellect Disabil. 2013;26:63-70.

10. Ravoux P, Baker P, Brown H. Thinking on your feet: understanding the immediate responses of staff to adults who challenge intellectual disability services. J Appl Res Intellect Disabil. 2012;25:189-202.

11. Robertson JP, Collinson C. Positive risk taking: whose risk is it? An exploration in community outreach teams in adult mental health and learning disability services. Health Risk Soc. 2011;13:147-164.

12. Hawkins R, Redley M, Holland A. Duty of care and autonomy: how support workers managed the tension between protecting service users from risk and promoting their independence in a specialist group home. J Intellect Disabil Res. 2011;55:873-884.

13. Bosworth M, Hoyle C, Dempsey MM. Researching trafficked women on institutional resistance and the limits to feminist reflexivity. Qual Inq. 2011;17:769-779.

14. Phillips N, Rose J. Predicting placement breakdown: individual and environmental factors associated with the success or failure of community residential placements for adults with intellectual disabilities. J Appl Res Intellect Disabil. 2010;23:201-213.

15. Frampton I, Mcarthur C, Crowe B, Linn J, Lovering K. Beyond parent training: predictors of clinical status and service use two to three years after Scallywags. Clin Child Psychol Psychiatry. 2008;13: 593-608.

16. Lovering K, Frampton I, Crowe B, Moseley A, Broadhead M. Community-based early intervention for children with behavioural, emotional and social problems: evaluation of the Scallywags Scheme. Emotional and Behavioural Difficulties. 2006;11:83-104.

17. Parsons S, Daniels H, Porter J, Robertson C. Resources, staff beliefs and organizational culture: factors in the use of information and communication technology for adults with intellectual disabilities. J Intellect Disabil Res. 2008;21:19-33.

18. Campbell M. Cognitive representation of challenging behaviour among staff working with adults with learning disabilities. Psychol Health Med. 2007;12:407-420. 
19. Hegarty JR, Aspinall A. The use of personal computers with adults who have developmental disability: outcomes of an organisation-wide initiative. The British Journal of Development Disabilities. 2006;52: $137-154$.

20. Hawkins S, Allen D, Jenkins R. The use of physical interventions with people with intellectual disabilities and challenging behaviour - the experiences of service users and staff members. J Appl Res Intellect Disabil. 2005;18:19-34.

21. Turbett C. Rural social work in Scotland and eastern Canada: A comparison between the experience of practitioners in remote communities. Int Soc Work. 2006;49:583-594.

22. Wilson E, Seymour J, Aubeeluck A. Perspectives of staff providing care at the end of life for people with progressive long-term neurological conditions. Palliat Support Care. 2011;9:377-385.

23. Beacroft M, Dodd K. Pain in people with learning disabilities in residential settings - the need for change. British Journal of Learning Disabilities. 2010;38:201-209.

24. Lowe K, Jones E, Horwood S, et al. The evaluation of periodic service review (PSR) as a practice leadership tool in services for people with intellectual disabilities and challenging behaviour. Tizard Learning Disability Review. 2010;15:17-28.

25. Kroese BS, Rose J, Heer K, O’Brien A. Mental health services for adults with intellectual disabilities - what do service users and staff think of them? J Appl Res Intellect Disabil. 2013;26:3-13.

26. Plath D. Organisational processes supporting evidence-based practice. Adm Soc Work. 2013;37:171-188.

27. Kleinberg I, Scior K. The impact of staff and service user gender on staff responses towards adults with intellectual disabilities who display aggressive behaviour. J Intellect Disabil Res. November 6, 2012. [Epub ahead of print.]

28. Sawyer A-M. Mental health workers negotiating risk on the frontline. Australian Social Work. 2009;62:441-459.

29. Broadhead M, Chilton R, Stephens V. Utilising the Boxall profile within the Scallywags service for children with emotional and behavioural difficulties. British Journal of Special Education. 2011;38: 19-27.

30. Broadhead M, Hockaday A, Zahra M, Francis P, Crichton C. Scallywags - an evaluation of a service targeting conduct disorders at school and at home. Educational Psychology in Practice. 2009;25 167-179.

31. Lawrence V, Banerjee S. Improving care in care homes: a qualitative evaluation of the Croydon care home support team. Aging Ment Health. 2010;14:416-424.

32. Roberts D, Hurst K. Evaluating palliative care ward staffing using bed occupancy, patient dependency, staff activity, service quality and cost data. Palliat Med. 2012;27:123-130.

33. Bartlett A, Clarke B. An exploration of health care professionals' beliefs about caring for older people dying from cancer with a coincidental dementia. Dementia. 2012;11:559-565.

34. Dryden H, Addicott R. Evaluation of a pilot study day for health care assistants and social care officers. Int J Palliat Nurs. 2009;15:6-11.

35. Nazarko L. Falls Part 4: prevention, assessment and intervention. British Journal of Health Care Assistants. 2008;2:535-539.

36. Ireland S, Lazar T, Mavrak C, et al. Designing a falls prevention strategy that works. J Nurs Care Qual. 2010;25:198-207.

37. Ford MT, Tetrick LE. Relations among occupational hazards, attitudes, and safety performance. J Occup Health Psychol. 2011;16:48-66.

38. Wood AJ, Schuurs SB, Amsters DI. Evaluating new roles for the support workforce in community rehabilitation settings in Queensland. Aust Health Rev. 2011;35:86-91.
39. Drummond A, Coole C, Brewin C, Sinclair E. Hip precautions following primary total hip replacement: a national survey of current occupational therapy practice. Br J Occup Ther. 2012;75:164-170.

40. Yip K-S. Medicalization of social workers in mental health services in Hong Kong. British Journal of Social Work. 2004;34:413-435.

41. Yip K-S. Controversies in psychiatric services in Hong Kong: social workers' superiority and inferiority complexes. Int Soc Work. 2004; 47:240-258.

42. Graham H. Implementing integrated treatment for co-existing substance use and severe mental health problems in assertive outreach teams: training issues. Drug Alcohol Rev. 2004;23:463-470.

43. Massey BF Jr. For the sake of our patients, it is the right thing to do. Phys Ther. 2005;85:1238-1242.

44. O'Leary KM. Two national surveys of hospital pharmacy technician activities to support the review of national qualifications. Journal of Pharmacy Practice and Research. 2012;42:43-47.

45. Maslanka E, Leach HJ. Expanding the role of a pharmacy technician in a private hospital. Journal of Pharmacy Practice and Research. 2004;34:131-132.

46. McKee J, Zimmerman M. Tech-check-tech pilot in a regional public psychiatric inpatient facility. Hosp Pharm. 2011;46:501-511.

47. Niazkhani Z, Pirnejad H, van der Sijs H, Aarts J. Evaluating the medication process in the context of CPOE use: the significance of working around the system. Int J Med Inform. 2011;80:490-506.

48. Hall KW, Raymond CB, Woloschuk DM, Honcharik N. Organizational restructuring of regional pharmacy services to enable a new pharmacy practice model. Can J Hosp Pharm. 2011;64:451-456.

49. Hon C-Y, Teschke K, Chua P, Venners S, Nakashima L. Occupational exposure to antineoplastic drugs: identification of job categories potentially exposed throughout the hospital medication system. Saf Health Work. 2011;2:273-281.

50. Lee SG, Ambados F, Tkaczuk MN, Jankewicz GJ. Paclitaxel exposure and its effective decontamination. Journal of Pharmacy Practice and Research. 2009;39:181-185.

51. Tkaczuk M, Lee SG, Jankewicz G, Ambados F. Surface contamination of cytotoxic drug 5-fluorouracil (5-FU) and decontamination. Journal of Health, Safety and Environment. 2010;26:171-181.

52. Duggan C, Mooney C, Roberts P, et al. Becoming a good leader-developing the skills required. Hospital Pharmacist. 2007;14:193-194

53. Herrera H. Foundation degrees - building on the foundation of experience. Hospital Pharmacist. 2007;1:311-312.

54. Conroy S, Appleby K, Bostock D, Unsworth V, Cousins D. Medication errors in a children's hospital. Paediatr Perinat Drug Ther. 2007;8: $18-25$

55. Holding D. Starting a pharmacy technician-led drug round. Hospital Pharmacist. 2004;11:477-478.

56. Orchiston M. Coordinating a medical gases service. Hospital Pharmacist. 2003;10:324-327.

57. Tempest A. Auditing the recording of allergy status in community hospitals. Hospital Pharmacist. 2006;13:259-260.

58. Sedgwick T. Improving medicines management for older patients on the move. Hospital Pharmacist. 2006;13:226-228.

59. Moulder B. Why not ask a technician to promote better prescribing? Hospital Pharmacist. 2004;11:397-398.

60. Siang CS, Ni KM, bin Ramli MN. Outpatient prescription intervention activities by pharmacists in a teaching hospital. Malaysian Journal of Pharmacy. 2003;1:86-90. 


\section{Publish your work in this journal}

The Journal of Multidisciplinary Healthcare is an international, peerreviewed open-access journal that aims to represent and publish research in healthcare areas delivered by practitioners of different disciplines. This includes studies and reviews conducted by multidisciplinary teams as well as research which evaluates the results or conduct of such teams or health-

care processes in general. The journal covers a wide range of areas and welcomes submission from practitioners at all levels, from all over the world. The manuscript management system is completely online and includes a very quick and fair peer-review system. Visit http://www.dovepress. com/testimonials.php to read real quotes from published authors.

Submit your manuscript here: http://www.dovepress.com/journal-of-multidisciplinary-healthcare-journal 